\title{
Erratum to: Adverse Gastrointestinal Events with Intravitreal Injection of Vascular Endothelial Growth Factor Inhibitors: Nested Case-Control Study
}

\author{
Robert J. Campbell • Chaim M. Bell • Susan E. Bronskill • \\ J. Michael Paterson • Marlo Whitehead • \\ Erica de L. Campbell $\cdot$ Sudeep S. Gill
}

Published online: 22 August 2014

(c) Springer International Publishing Switzerland 2014

\section{Erratum to: Drug Saf \\ DOI 10.1007/s40264-014-0211-6}

An error was subsequently identified in the article, and the following correction should be noted:

\section{Section 3.1, paragraph 1, lines 2-4}

The following sentence, which previously read:

"Within this base cohort, we identified 3,589 cases, 77 of which could not be matched to a control patient."

The online version of the original article can be found under doi:10.1007/s40264-014-0211-6.

\section{R. J. Campbell ( $\varangle)$ · E. de L. Campbell}

Department of Ophthalmology, Queen's University,

Kingston, ON, Canada

e-mail: rob.campbell@queensu.ca

\section{R. J. Campbell · E. de L. Campbell}

Department of Ophthalmology, Hotel Dieu and Kingston General Hospitals, 166 Brock Street, Kingston,

ON K7L 5G2, Canada

R. J. Campbell · C. M. Bell · S. E. Bronskill ·

J. M. Paterson - M. Whitehead - S. S. Gill

Institute for Clinical Evaluative Sciences (ICES-Central),

G1 06, 2075 Bayview Avenue, Toronto,

ON M4N 3M5, Canada

C. M. Bell

Department of Medicine, University of Toronto,

Toronto, ON, Canada

C. M. Bell · S. E. Bronskill · J. M. Paterson Institute of Health Policy Management and Evaluation,

University of Toronto, Toronto, ON, Canada

C. M. Bell

Department of Medicine, Mount Sinai Hospital,

Toronto, ON, Canada should read:

"Within this base cohort, we identified 3,589 cases, 7 of which could not be matched to a control patient."

C. M. Bell

Department of Medicine, St. Michael's Hospital,

30 Bond Street, Toronto, ON M5B 1W8, Canada

J. M. Paterson

Department of Family Medicine,

McMaster University, Hamilton, ON, Canada

M. Whitehead

Institute for Clinical Evaluative Sciences

(ICES@Queen's), Abramsky Hall, Queen's University,

21 Arch St, Kingston, ON K7L 3N6, Canada

S. S. Gill

Division of Geriatric Medicine,

Queen's University, Kingston, ON, Canada

S. S. Gill

Division of Geriatric Medicine, St. Mary's of the Lake Hospital, 340 Union St, Kingston, ON K7L 5A2, Canada 